\title{
Consultative work in child and adolescent psychiatry
}

\author{
Derek Steinberg
}

This is the ninth of a series of articles on treatment of child psychiatric disorders.
It should be said at the outset in a paper in a series on treatment that, of course, consultation is not a form of therapy. Indeed, in some important ways it can be seen as, at times, an alternative to therapy.

For historic reasons, because of the nature of the problems with which we deal, and because of the relatively ill defined (and perhaps undefinable) boundaries to our professional territory, psychiatrists are approached about a much wider range of problems than are attributable to psychiatric disorder, or which need psychiatric care. Every seriously unhappy or misbehaving child could at least in principle be taken on by a child psychiatrist. This, however, would make no more sense than to say that the 'right' professional would be a psychologist, or psychotherapist, or family therapist; or a paediatrician, general practitioner, health visitor, or counsellor with the appropriate skills and interests for that matter. (And there are some 30 or 40 other workers one could list.) It often isn't clear who is in the best position to help which child and family with whatever presents as a psychiatric problem. It depends not only on the clinical symptomatology, if any, but on the skills, strengths, availability, motivation, and interests of the other people involved with the child. This includes his or her parents and non-clinicians such as teachers.

\section{Definitions}

In this context the term consultation represents a set of techniques and approaches by which one professional can help another, not necessarily by taking over the child's case (although this can remain an option), but by seeing if he or she can help the first worker to manage the child's case after all. At the most basic descriptive level, consultation is about one professional (the consultant) helping another (the consultee) with a problem but without taking over care or professional responsibility. In this sense it differs from traditional clinical consultation, where the doctor sees and treats the patient. To avoid confusion I have recommended the term interprofessional consultation ${ }^{1}$ for the work described here.

What is interesting about interprofessional consultation (and having thus identified it, I will revert to 'consultation' for short) is the complex range of implications of this relatively simple and straightforward definition. Consultation may involve, for example, a child psychia- trist and a paediatrician discussing a case in a way which leaves the referring professional feeling he or she would like to carry on with the patient concerned, and reasonably confident about doing so. In this example, the consultant may have helped the consultee appreciate what he or she can after all do for a child who was thought at first to need psychiatric care. But consultation can also involve a visiting doctor helping the staff of, for example, a school or children's home develop ways of handling a misbehaving boy effectively enough to avoid him having to be seen at a psychiatric clinic; and as a result, ideally, handling a proportion of other children more effectively too.

This may invite the question whether consultation is no more than a substitute for clear criteria for referral to a psychiatric clinic. However, while the criteria, say, for the referral of a child with the symptoms of meningitis or appendicitis from a generalist to a specialist are clear, decisions about when or whether people have reached the limits of their resources in handling unhappy, misbehaving, or otherwise malfunctioning children are less clear-cut. They bring in a whole set of other variables, such as ideas, imagination, problem solving skills, staff consistency and, not least, opporrunities (or the lack of them) to get together andronsider what to do in a reasonably calm, systematic, and focused way. It is a constant surprise in consultative work to find how frequently staff involved in child care can do more than they initially thought, when the only authority the outside consultant brings is 'permission' to stand back for half an hour from the tension and hurly-burly of the work, and the skill to help them look again at what they are trying to do and how they are trying to do it. ${ }^{1-3}$

This implies a further important characteristic of consultative work: that the point is not for the consultant to bring his or her own methods and concepts to bear on the issue at hand, but to seek to mobilise those of the consultees. The psychiatrist consulting to, say, a paediatric clinic, school, or children's home doesn't try to treat the children 'through' the paediatrician, teachers or residential staff but uses consultative approaches to mobilise paediatric, teaching, and residential care experience and skill.

Of course, at first sight this may seem like a professional ploy akin to a jobbing gardener persuading his employer to do the digging, perhaps indicating that providing a better spade for the employer and a deckchair for the 
gardener might not come amiss. However, a central point in consultatation is that any of us may be able to manage a particular case or issue better than we initially supposed given a focused opportunity, encouragement, and help in what is essentially a problem solving exercise. If this works, and the admittedly limited research into consultation suggests that it can, ${ }^{2-5}$ then the consultative process is an educational exercise as well as a way of handling day to day practical matters. Instead of being told what to do, shown what to do, or having the job taken over by someone who is supposedly more expert, the consultee learns something new. All of us, in our roles as teachers or trainees, know that this is an effective style of training, applicable to many (though not every) situation.

There is also an important reciprocity in the consultative relationship. The person who for this particular issue is the consultant does not take a superior stance, for example indicating that the other person should surely be able to work it out for himself. Rather, the joint exploration of what a colleague has indicated is a problem is a learning exercise for the consultant too. The outcome of, say, a surgeon consulting in this way with a physician should mean that each learns something about the other's work that they didn't know before. I would say that the most important single quality of a good consultant is curiosity; a genuine wish to find out what goes on in the other's field, the nature of the problems that arise, how they might be clarified, and how resolved.

\section{The value of consultation}

There are benefits of consultation thatpotentially-make the whole exercise worth while. I say potentially because the field is relatively new, that is about 20 years from its inception, and needs more evaluative research. But on the face of it one can suggest the following advantages:

(1) As already indicated, it can be educational. If I set out to refer an anxiety-making diabetic adolescent to a physician and, instead, the physician helped me explore how I can help the adolescent and the family manage the diabetes more effectively and responsibly, then I would learn a great deal more than had the other doctor simply taken over. I might well find that I not only handle that patient's case better, but future cases too.

(2) Second, it may enable the patient to stay with the original practitioner instead of having another appointment with another clinician in another unit or hospital. How much time is taken up by patients in transit, or 'stacked' around clinics? This is not only a question of the convenience of those involved, but also concerns continuity of care, which is of particular importance in child and adolescent psychiatry, whether one is trying to ensure stability of relationships or the success of a behaviour therapy programme. (For example an autistic, unhappy, or misbehaving child is more likely to benefit from those in touch with them doing the right thing throughout the week, than from a psychiatrist doing something brilliant once a week in the clinic.)
(3) If it should emerge, immediately in consultation or later on, that the patient (or an aspect of care) would indeed be best taken over by the second professional worker, then the small amount of time 'lost' in consultation is likely to prove to have been well spent in clarifying the nature of the problem, who should be doing what, and (of special importance in the child psychiatry field) where appropriate authority for action (for example admission, medication) is going to come from. Certainly in 'emergencies' in adolescent psychiatry the gains can certainly outstrip the imagined problems when an admission to hospital, or an urgent and unplanned appointment, is held off for a little to allow for consultation between those already involved and those who are about to become involved. ${ }^{6-9}$

As was mentioned earlier, there are many different types of worker in the broad field of child care and mental and physical health. The field is kaleidoscopic. If the first professional approached (and this too is quite arbitrary-he or she may happen to be for example a teacher, a health visitor, a general practitioner, a paediatrician, a psychiatrist, a psychologist, or a counsellor, among others) feels out of his or her depth, it is often not absolutely clear to whom a rereferral should be made. If the art of good consultation were part of the professional repertoire of all such specialist workers, it might well be possible to make more economical and more speedy use of the immensely complex network we have of different types of skill and service.

(4) There is another value of consultation which I will refer to only briefly. So far I have suggested consultation as an effective way of problem solving and establishing the most appropriate help available. However, there is a great deal of ethical as well as technical controversy in medicine, and dilemmas for example about behaviour, education, social and family norms and expectations, HIV testing, genetic issues, high technology health care, alternative medicine, and sexual experience and behaviour which cannot be resolved by negotiation and information alone. The subjective views and the values of different practitioners, families, and indeed children themselves also need taking into account, and again the consultative process provides a forum for sorting out not only what is supposedly needed but what is wanted. Questions of the law relating to children ${ }^{10}$ and of informed consent ${ }^{11}$ can also be addressed in this way.

To sum up what is being presented as the value of consultation: in an increasingly complex, diverse, and changing field of need on the one hand and services on the other, consultation can be a more effective way than the traditional 'referral' of sorting out who is most able and willing to do what. And, further, it is a method which educates all sides as it proceeds.

\section{The theoretical bases for consultation}

Consultative approaches draw on a number of theoretical models. The figure suggests the various areas on which consultation might focus 


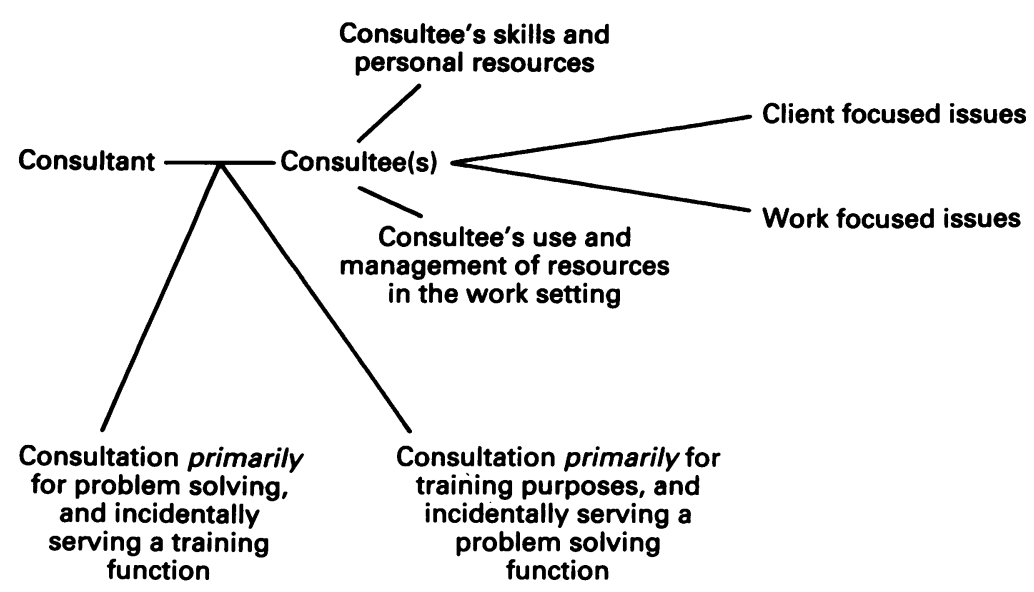

Areas of work in consultation. areas, whose practical implications and conceptual roots may be in, for example, social science, ethics, anthropology, or politics. ${ }^{9} 11-13$ This can cause problems, as is discussed below.

\section{Practical aspects of consultation}

Consultation may therefore be centred upon the consultee, that is in terms of thinking through and reviewing how he or she has been dealing with an issue, on a clinical or organisational issue the consultee identifies, or on the work setting. Of course, with mutual agreement, the focus can shift if that is appropriate.

Consultation has already been described as an activity where the style of problem solving leads also to further learning. It is important to note that further learning can also be the primary purpose of a piece of consultative work, for example if a child care team asks an outside consultant to help it develop its skills or the way it is organised, using day to day work issues as training material.

Consultation may be informal and ad hoc, for example a meeting over coffee, or in the way a referral or other inquiry is handled. It may involve two people, or a group, and may happen over a specific number of sessions or indefinitely. problem solving. It is essentially a joint exploration and negotiation, not about power but about how best to clarify an issue or problem and manage it. 1247

Second, there is the relationship between the consultee and 'the problem'. So far, this has been discussed in terms of a patient's problem, so this dimension of the figure is about clinical skills. We don't operate at peak efficiency all the time, especially when under pressure, and consultation, simply by creating a piece of focused space and time to take another look at a problem can enable us to use our clinical skills more effectively. Having said this, the question in hand is not invariably a clinical one; an organisational issue is also a legitimate subject to consult about, and again in the relative calm, it is to be hoped, of a consultation it is possible to look again at managerial, interprofessional, or other matters that need attention.

Thus far, then, consultation is described in terms of helping to mobilise personal skills. But another possible focus for consultative work is that which is available, or missing, in the work setting - for example facilities, personnel, and such basics as time (and timetabling) and space. It is interesting how often what may look at first like a clinical problem, or a problem of personal skills, can emerge as a primarily organisational problem. ${ }^{1-3}$ The process of systematic joint inquiry about the precise nature of the problem, and precisely what is needed, can come up with some surprising results: that a child care team, for example, does not have effective support or supervision, or that a department has a chaotic timetable, conflicting goals, or confused decision making and communication systems.

Part of the interest and challenge of consultative work is that the process of objective, shared inquiry into precisely what impedes and what enhances work may well lead into unexpected

\section{Problems in consultation}

(A) MISUNDERSTANDING

If it is consultation as described here that is being sought or offered, that should be made clear. For example, if the transfer of responsibility to another clinician, or the transfer of care from one unit or ward to another (the term 'disposal' is sometimes used) is wanted, it is annoying to be offered consultation instead. Such things happen, for example in intensive care areas.

\section{(B) IS CONSULTATION TIME CONSUMING ?}

The question is rather to do with whose time is consumed, and when. Writing a referral note to a clinic, where a patient and parents are booked into a clinic some weeks hence, may take just a few minutes in terms of staff time. A detailed clinical assessment, perhaps after a wait of several weeks, may use many hours and turn out to be not necessary. A consultative response to referrals, or at least to some of them, may actually save time, enabling a more finely modulated response (G Savoury et al, unpublished observations). ${ }^{2}{ }^{7}$ But it may not seem that way, and sometimes it may not be that way.

\section{(c) CONSULTING AT THE WRONG LEVEL}

It is an assumption of consultation that the consultee is at least potentially able, with help, to handle the matter in hand. However, if a problem looks like a clinical one (for example a registrar or staff nurse in difficulties over a case in an intensive care unit) but the answer lies in matters of policy (for example in terms of the medical or nursing training or supervision 
provided there), then the consultation will run into difficulties. Part of the skill of consultation is in checking that consultation is appropriate, with whom, and with what focus.

\section{(D) STRAYING INTO OTHER TERRITORY}

Consultation is something of a balancing act. It is not 'support', or psychotherapy, or supervision, or about intervening in local politics or administration, and yet approaches the edge of these areas. This is not simply a fine point of semantics. It is possible to get into real difficulty, and may be professionally and legally hazardous, if you believe you are offering consultation as defined here to a children's home, while the local authority believe you are supervising its staff. Such muddles happen.

\section{(E) CONFIDENTIALITY}

Confidentiality is sometimes an unexpected problem. For academic purposes it is easier to preserve the confidentiality of a patient than an institution and its staff. There is also the problem of the consultant being unhappy about, say, practices in a children's home, or problems in the staff, and finding that consultation is making no impact. The expectation of consultation that all participants are expected to be responsible, within their roles and levels of expertise, is a help here rather than a hindrance, because if consultees cannot learn from consultation there should be a mutual agreement to end it. Perhaps supervision is needed instead. If a consultant discovered serious malpractice the same would apply, and if none of the consultees were willing to explain it to the appropriate authority the consultant, in a different role, might have to instead.

\section{(F) EXCESSIVE PURITY}

Consultation needs to be reasonably clearly defined and its brief adhered to. At the same time it should be pragmatic and helpful, and should not become locked into a particular ideology. Thus the aim not to overlap with clinical work should not be used to defy common sense if, for example, a doctor consulting to the staff of a children's home or a school suspected that a misbehaving child had a psychiatric problem. If there is an impasse over this or any other sort of problem there is an in- built solution: consult the consultees and review what you are doing; it is all grist to the consultative mill. Moreover, consultative and clinical approaches can be explicitly used together in a dual consultative-diagnostic approach, in which tasks are shared out as, for example, those for the social worker, those for the parents, those for the school, those for the clinician, and indeed those for the child. This is particularly helpful in child and adolescent psychiatric practice, where 'who does what' can be contentious. $6-911$

\section{Conclusion}

In child and adolescent psychiatry, and I would suggest in related fields too, it is often not obvious which professional worker is the most appropriate for which type of presenting problem. Moreover, it often happens that several people are needed to work together, sometimes on an ad hoc basis, for a particular child's case. I doubt whether this could ever be worked out as part of a 'grand design', or by computer. Consultation, as a collaborative skill all specialists could usefully have, offers a helpful way of clarifying who should do what with whom in a particular child's case, and it educates, and studies the field, as it proceeds.

This paper is based on a talk given to the Congress of the European Society for Paediatrics held in Athens in October 1990.

1 Steinberg D. Interprofessional consultation. Oxford: Blackwell Scientific Publications, 1989.

2 Caplan G. The theory and practice of mental health consultation. London: Tavistock Publications, 1970.

3 Steinberg D, Hughes L. The emergence of work-centred issues in consultative work. 7 Adolesc 1987;10:309-16.

4 Conoley JC. Consultation in schools: theory, research, procedures. New York: Academic Press, 1981.

5 Gallesich J. The profession and practice of consultation. London: Jossey-Bass, 1982.

6 Steinberg D. Basic adolescent psychiatry. Oxford: Blackwell Scientific Publications, 1987.

7 Steinberg D. Management of crises and emergencies. In: Hsu LK, Hersen M, eds. Recent developments in adolescent LK, Hersen M, eds. Recent developments in

8 psychiatry. New York: Wiley Interscience, 1989 . calities. In: Brook CGD, ed. Adolescent medicine. Sevenoaks, calities. In: Brook CGD, ed. Adolesc
Kent: Edward Arnold (in press).

9 Steinberg D. The clinical psychiatry of adolescence. Chichester: Wiley, 1983.

10 Department of Health. The Children Act, 1989. London: HMSO, 1989.

1 Steinberg D. Informed consent: consultation as a basis for collaboration between disciplines and between professionals and their patients. Foumal of Interprofessional Care 1992;6: 43-8.

12 Caplan G. Principles of preventive psychiatry. London: Tavistock Publications, 1964.

13 Trist E, Murray $\mathrm{H}$, eds. The social engagement of social science. I: The socio-psychological perspective. London: Free Association Books, 1990. 